\title{
Reação de híbridos de milho à mancha-de-macrospora
}

\author{
Giovani Jian Piletti ${ }^{1}$, Ricardo Trezzi Casa ${ }^{2}$, Daiana Bampi ${ }^{3}$, Ligia Maria Maraschi da Silva Piletti ${ }^{4}$, Juan Carlo Stoltz , \\ Luis Sangoi ${ }^{2}$, Davi Michelutti ${ }^{2}$
}

${ }^{1}$ Mestrando do Curso de Produção Vegetal da Universidade do Estado de Santa Catarina, UDESC, Av. Luiz de Camões, 2090. Bairro Conta Dinheiro, CEP 88520-000, Lages-SC; ${ }^{2}$ Professores do Curso de Pós-Graduação em Produção Vegetal, UDESC; ${ }^{3}$ Doutoranda do Curso de Proteção de Plantas, Universidade Estadual Paulista Júlio de Mesquita Filho, UNESP, Campus de Botucatu-SP; ${ }^{4}$ Doutoranda em Produção Vegetal da Universidade Federal da Grande Dourados, UFGD, Dourados-MS; ${ }^{5}$ Acadêmico do curso de Agronomia, UDESC.

Autor para Correspondência: Giovani Jian Piletti (giovani-piletti@hotmail.com)

Data de chegada: 10/07/2013. Aceito para publicação em: 13/01/2014.

\section{RESUMO}

Piletti, G.J.; Casa, R.T.; Bampi, D.; Piletti, L.M.M.S.; Stoltz, J.C.; Sangoi, L.; Michelutti, D.. Reação de híbridos de milho à mancha-de-macrospora. Summa Phytopathologica, v.40, n.1, p.24-28, 2014.

\begin{abstract}
A mancha-de-macrospora, causada pelo fungo Stenocarpella macrospora, tem se mostrado frequente e importante na cultura do milho no Brasil. A resistência genética é uma das principais estratégias de controle de doenças foliares do milho. No Brasil, são escassas as informações sobre resistência de híbridos à S. macrospora. O objetivo deste trabalho foi avaliar a reação de 25 híbridos de milho à mancha-de-macrospora. $\mathrm{O}$ experimento foi conduzido em 2011, em casa de vegetação com condições controladas de temperatura e umidade relativa do ar. $\mathrm{O}$ delineamento experimental foi inteiramente casualizado, com cinco repetições, sendo as unidades experimentais constituídas por um vaso com cinco plantas. A inoculação foi feita no estádio fenológico V2 (duas folhas totalmente expandidas), depositando no cartucho de cada planta $2,0 \mathrm{~mL}$ da suspensão de $1,8 \times 10^{4}$ conídios $\mathrm{mL}^{-1}$
\end{abstract}

do patógeno. Foram utilizados quatro isolados do fungo obtidos de restos culturais infectados, oriundos dos municípios de Lages e de Quilombo, Santa Catarina, e Campinas do Sul e Vacaria, Rio Grande do Sul. A severidade da doença foi avaliada aos 21 dias após a inoculação no estádio V4 (quatro folhas totalmente expandidas). Nenhum híbrido testado mostrou-se totalmente resistente ao fungo $S$. macrospora. Houve diferença significativa na severidade da doença entre híbridos e isolados do fungo. Híbridos inoculados com o isolado Quilombo apresentaram quatro grupos de reação, e os isolados Vacaria, Lages e Campinas do Sul dois grupos. Alguns híbridos se comportaram de maneira distinta frente aos diferentes isolados, sugerindo diferentes níveis de agressividade. Houve híbridos com reação similar entre os isolados, sugerindo maior estabilidade em relação à mancha-de-macrospora.

Palavras-chave adicionais: Diplodia, resistência genética, Stenocarpella macrospora, Zea mays

\section{ABSTRACT}

Piletti, G.J.; Casa, R.T.; Bampi, D.; Piletti, L.M.M.S.; Stoltz, J.C.; Sangoi, L.; Michelutti, D.. Resistance of corn hybrids to macrospora leaf spot Summa Phytopathologica, v.40, n.1, p.24-28, 2014.

Macrospora leaf spot, caused by the fungus Stenocarpella macrospora, has shown to be frequent and important among corn fields in Brazil. Genetic resistance is one of the main strategies to control corn leaf diseases. In Brazil, there is scarce information on the resistance of hybrids to Stenocarpella macrospora. The aim of this study was to evaluate the reaction of 25 corn hybrids to macrospora leaf spot. The experiment was conducted in 2011, in a greenhouse under controlled temperature and relative humidity conditions. Experimental design was completely randomized, with five replicates, each experimental unit consisting of a pot with five plants. Inoculation was done in the V2 growth stage (two fully expanded leaves), and the whorl of each plant received $2.0 \mathrm{~mL}$ suspension of $1.8 \times 10^{4}$ conidia $\mathrm{mL}^{-1}$ pathogen. The four used fungal isolates were obtained from infected crop residues at the municipalities Lages and Quilombo, Santa Catarina State, and Campinas do Sul and Vacaria, Rio Grande do Sul State. Disease severity was assessed at 21 days after inoculation in the V4 stage (four fully expanded leaves). No tested hybrid was totally resistant to the fungus $S$. macrospora. There was a significant difference in the disease severity between hybrids and fungal isolates. Hybrids inoculated with Quilombo isolate showed four reaction groups, while the isolates Vacaria, Lages and Campinas do Sul showed two groups. Some hybrids had varied behaviors against the isolates, suggesting different aggressiveness levels. There were hybrids that showed similar reaction to the isolates, suggesting greater stability for macrospora leaf spot.

Additional keywords: Diplodia, genetic resistance, Stenocarpella macrospora, Zea mays

O milho (Zea mays L.) é uma das principais culturas exploradas no Brasil. A importância desse cultivo é caracterizada pela sua utilização na alimentação humana e animal. A área semeada e a produção vêm aumentando nas últimas décadas, porém a produtividade brasileira é considerada baixa se comparada ao potencial produtivo da cultura $(9,12)$.

As doenças foliares afetam a produtividade do milho $(2,13)$. A mancha-de-macrospora, causada pelo fungo necrotrófico Stenocarpella 
macrospora (Earle) Sutton [Sin. Diplodia macrospora Earle], tem se mostrado frequente e importante na cultura do milho nos últimos anos no Brasil (5). Além de mancha foliar, o fungo pode causar podridão do colmo, podridão da espiga e grãos ardidos (23). Em híbridos de milho suscetíveis, causa lesões foliares diminuindo a área fotossintetizante da planta (16), podendo servir como fonte de inóculo para infecções da espiga, o que afeta a produtividade e a sanidade do grão $(1,15)$.

A sobrevivência saprofítica de $S$. macrospora nos restos culturais infectados de milho tem tornado a doença frequente devido às extensas áreas semeadas no sistema semeadura direta e monocultura, pois a palha infectada que permanece na superfície do solo, garante a sobrevivência e a viabilidade do fungo (6). A disseminação do fungo ocorre via semente infectada, sendo este mecanismo responsável pela introdução do patógeno em novas áreas de cultivo (25), ou por respingo de chuva e/ ou pelo vento a curtas distâncias pela remoção e dispersão dos conídios presentes nos restos culturais (7).

Temperaturas entre 25 e $32{ }^{\circ} \mathrm{C}(11)$, com umidade relativa do ar acima de $50 \%$ (16) são condições ideais para germinação dos conídios do fungo. Os conídios de $S$. macrospora germinam no tecido da folha entre 12 e 15 h após sua deposição, sob temperatura de $28^{\circ} \mathrm{C}(3,20)$.

A resistência genética é o método mais eficiente e econômico de controle das doenças foliares em milho (21). Contudo, quando aliada a outras práticas como o controle cultural ou químico, fornece maior sustentabilidade a cultura. O fato de $S$. macrospora infectar exclusivamente plantas de milho, não formar estrutura de repouso e apresentar conídios dispersados a curtas distâncias, são características biológicas do patógeno que permitem manejá-lo com a rotação de culturas e o uso de sementes sadias e/ou tratadas com fungicidas eficientes (8). O uso do controle químico, apesar de ser eficiente para o controle de algumas doenças foliares, aumenta o custo de produção e apresenta riscos de contaminação ao ambiente (28).

No Brasil, os híbridos comerciais de milho têm sido classificados em geral quanto a sua resistência às podridões do colmo e da espiga e em algumas situações em relação à incidência de grãos ardidos. Entretanto, não existe uma descrição clara da reação dos materiais genéticos especificamente para cada patógeno envolvido com os sintomas. Poucos são os relatos sobre a resistência genética de híbridos comerciais às espécies de Stenocarpella (8). Entretanto, não há ou são escassas e imprecisas, informações sobre a resistência genética de híbridos de milho para mancha foliar causada por $S$. macrospora $(4,10$, $18,19)$. Também não há relatos da presença de raças de $S$. macrospora, mas sabe-se da existência de variação na agressividade entre diferentes isolados do patógeno (4).

O conhecimento do nível de resistência dos genótipos é uma ferramenta importante para indicação de cultivares em regiões com epidemias frequentes da doença.

Este trabalho teve como objetivo obter informações a respeito dos níveis de resistência em cultivares comerciais de milho a isolados de $S$. macrospora provenientes de quatro regiões do sul do Brasil.

\section{MATERIAL E MÉTODOS}

O experimento foi conduzido em casa de vegetação, no Centro de Ciências Agroveterinárias da Universidade do Estado de Santa Catarina, Lages, $\mathrm{SC}$, com temperatura de $25^{\circ} \mathrm{C} \pm 3^{\circ} \mathrm{C}$ e umidade relativa do ar em torno de $70 \%$.

O delineamento experimental foi inteiramente casualizado, com cinco repetições, sendo cada unidade experimental constituída por um vaso com cinco plantas, totalizando 25 plantas por tratamento. Foram avaliados 25 híbridos (Tabela 1) obtidos de cooperativas do estado catarinense. Foram utilizados quatro isolados do fungo obtidos de trinta colmos de milho naturalmente infectados e coletados do mesmo híbrido e numa mesma lavoura, nos municípios de Lages e Quilombo, Estado de Santa Catarina, e Vacaria e Campinas do Sul, Estado do Rio Grande do Sul.

As sementes de cada híbrido de milho foram semeadas em vasos plásticos com capacidade 1,5 litros, contendo uma mistura homogênea de substrato agrícola composto de casca pinus (80\%) e vermiculita $(20 \%)$. Foram semeadas oito sementes por vaso. As sementes foram cobertas com aproximadamente $2,5 \mathrm{~cm}$ de substrato. Os vasos foram mantidos em casa de vegetação e irrigados de acordo com as necessidades hídricas da cultura. No estádio fenológico V2 (duas folhas totalmente expandidas) de acordo com a escala proposta por Ritchie (24), foi realizado o desbaste, deixando-se cinco plantas por vaso.

Para o preparo da suspensão de inóculo, os colmos infectados

Tabela 1. Híbridos de milho submetidos à avaliação da reação à mancha-de-macrospora. Lages, SC, 2011

\begin{tabular}{|c|c|c|c|c|c|}
\hline Híbrido & Tipo $^{1}$ & Ciclo $^{2}$ & Híbrido & Tipo $^{1}$ & Ciclo $^{2}$ \\
\hline 1. As 1565 & HS & $\mathrm{P}$ & 14. P 30F53 H & HS & $\mathrm{P}$ \\
\hline 2. As $1555 \mathrm{YG}$ & HS & $\mathrm{P}$ & 15. P 1630 & HS & SP \\
\hline 3. As 32 & HD & $\mathrm{P}$ & 16. P 30F53 H & HS & $\mathrm{P}$ \\
\hline 4. Ag 8025 & HS & $\mathrm{P}$ & 17. P 32R48 & HS & SP \\
\hline 5. Ag $8041 \mathrm{YG}$ & HS & $\mathrm{P}$ & 18. P 32R22 H & HS & SP \\
\hline 6. Attack TL & HSM & $\mathrm{P}$ & 19. P $1630 \mathrm{Y}$ & HS & SP \\
\hline 7. Celeron TL & HS & SP & 20. P 30R50 H & HS & $\mathrm{P}$ \\
\hline 8. Dkb $240 \mathrm{YG}$ & HS & $\mathrm{P}$ & 21. Penta TL & HS & $\mathrm{P}$ \\
\hline 9. Dkb 245 & HS & $\mathrm{P}$ & 22. Premium Flex & HS & $\mathrm{P}$ \\
\hline 10. Dkb $350 \mathrm{YG}$ & HT & $\mathrm{P}$ & 23. Status TL & HS & $\mathrm{P}$ \\
\hline 11.Dow 2b688 HX & HT & $\mathrm{P}$ & 24. Sprint TL & HS & HP \\
\hline 12. Maximus TL & HS & $\mathrm{P}$ & 25. Tork & HS & $\mathrm{P}$ \\
\hline 13. Maximus & HS & $\mathrm{P}$ & & & \\
\hline
\end{tabular}


foram desinfestados com hipoclorito de sódio (2\%) e submetidos à câmara úmida com temperatura de $30^{\circ} \mathrm{C}$ por 48 horas até a extrusão do cirro de conídios. Após, foi realizada raspagem dos colmos com pincel para remoção dos cirros com água destilada e esterilizada com duas gotas por litro do surfactante Tween 20. A suspensão foi filtrada com duas camadas de gaze para eliminar os fragmentos de material vegetal. Foi realizado o ajuste da concentração da suspensão com auxílio da câmara de Neubauer. A suspensão de $1,8 \times 10^{4}$ conídios $\mathrm{mL}^{-1}$ foi vertida no cartucho das plantas no estádio fenológico V2, com pipetador automático, depositando-se $2 \mathrm{~mL}$ por planta. Após 21 dias da inoculação, quando o milho estava no estádio fenológico V4, a quarta folha expandida de cada planta foi coletada para avaliação da severidade da doença. Mediu-se a área necrosada pelas lesões com um paquímetro digital para obtenção da severidade da doença em função da área foliar (A) estimada, aplicando-se a expressão $\mathrm{A}=\mathrm{C}$ x L x 0,75 , onde $\mathrm{C}$ é o comprimento e L é a maior largura da folha, conforme metodologia descrita por Tollenaar (27).

Os dados obtidos foram submetidos à análise da variância através do teste F. As comparações entre médias dos tratamentos foram feitas por meio do teste de Scott-Knott, considerando o nível mínimo de significância de 5\%. Comparações entre grupos foram feitas por contrastes também ao nível mínimo de significância de 5\%. A análise foi realizada a partir dos dados transformados por meio da expressão $\log X$.

\section{RESULTADOS E DISCUSSÃO}

Todos os genótipos avaliados apresentaram infecção e expressão dos sintomas causados por S. macrospora no estádio V4, com variação na severidade (Tabela 2). Não foi encontrado nenhum genótipo totalmente resistente ao fungo S. macrospora. Porém, houve variação no grau de severidade entre híbridos para cada isolado do fungo e entre os isolados testados, com exceção de Lages e Vacaria que não diferiram entre si (Tabelas 2 e 3 ).

A média da severidade da mancha-de-macrospora nos 25 híbridos foi de $8,98 \%$ para isolado Lages, 9,14\% para isolado Vacaria, 10,27\% para isolado Quilombo e 16,82\% para isolado Campinas do Sul (Tabela $3)$, demonstrando variação na severidade da doença ao se comparar os quatro isolados. O isolado de Campinas do Sul apresentou maior agressividade quando comparado aos demais, sendo que a severidade variou de $12,1 \%$ a $20,9 \%$, já para o isolado de Quilombo houve uma variação de $5,2 \%$ a $14,2 \%$, enquanto que para os isolados de Lages e Vacaria esta variação foi de $4,2 \%$ a $12,4 \%$ e $5,8 \%$ a $12,8 \%$ respectivamente. Quatro grupos estatísticamente distintos de híbridos foram observados quanto à severidade da doença para o isolado Quilombo e apenas dois grupos para os isolados Lages, Vacaria e Campinas do Sul (Tabela 2).

Sutoyo (26) constatou diferença significativa na severidade da mancha-de-macrospora, que variou de 4,79 a $30 \%$ aos 35 dias após a inoculação de 37 cultivares de milho no estádio de plântula, com inoculação de $2 \times 10^{5}$ conídios $\mathrm{mL}^{-1}$ de um isolado.

$\mathrm{O}$ híbrido que apresentou menor severidade à mancha-demacrospora foi o Premium Flex, considerando os isolados de Vacaria e de Lages, com severidade de 5,8\% e 3,2\%, respectivamente (Tabela 2). Para o isolado de Quilombo o híbrido P1630 mostrou menor severidade $(5,2 \%)$ e para o isolado de Campinas do Sul a menor severidade observada foi $12,10 \%$ para o híbrido AS1555YG, sendo estes considerados mais resistentes para estes isolados. Os híbridos mais suscetíveis à mancha-de-macrospora foram P30F53 HX com severidade de $12,4 \%$ para o isolado Lages, P30R50 HX com severidade de $12,8 \%$ para o isolado Vacaria, AS32 com severidade $14,2 \%$ para o isolado Quilombo e o híbridoAS1565 que apresentou severidade de $20,9 \%$ para o isolado de Campinas do Sul.

Para alguns híbridos foram observadas severidades semelhantes mesmo quando inoculados com isolados diferentes, mantendo o mesmo nível de resistência à S. macrospora independente do isolado utilizado, como por exemplo, os híbridos Maximus e Sprint TL que apresentaram comportamento estável em todos os isolados a que foram submetidos, e mantiveram-se em grupos considerados mais resistentes. O híbrido Maximus apresentou severidades de $7 \% ; 6,8 \% ; 8,8 \%$ e $14,6 \%$ quando inoculado com os isolados de Lages, Vacaria, Quilombo e Campinas do Sul, respectivamente. Enquanto para os mesmos isolados o híbrido Sprint TL apresentou severidades de $6,4 \% ; 7,0 \% ; 9,6 \%$ e $15,1 \%$. Cabe ressaltar que mesmo com severidades de $14,6 \%$ e $15,1 \%$, estes dois híbridos se enquadraram no grupo mais resistente à mancha-demacrospora, já que o isolado Campinas do Sul foi o que apresentou maior severidade de doenças nas plantas variando de $12,1 \%$ a $20,9 \%$.

Apresentando a mesma estabilidade, mas considerado mais suscetível à doença destacou-se o híbrido Atack TL com severidade de $10,4 \% ; 12,2 \% ; 11 \%$ e $19 \%$ para os isolados Lages, Vacaria, Quilombo e Campinas do Sul, respectivamente, enquadrando-se em grupos considerados de maior suscetibilidade para todos os isolados. Além destes, destacaram-se ainda os híbridos Tork TL, AS32 e Maximus TL TG, que também foram considerados mais suscetíveis à manchade-macrospora.

Entretanto, não é possível afirmar que este foi um comportamento geral, pois muitas cultivares apresentaram diferenças no valor de severidade em função dos diferentes isolados utilizados. Alguns híbridos apresentaram uma variabilidade genética em função do isolado utilizado como, por exemplo, os híbridos Dow2B688 HX, Celeron TL, AG8041 YG, P32R48 e Penta TL TC.

Ainda comparando os isolados, pode-se destacar que o de Vacaria e o de Lages foram muito semelhantes entre si, pois os híbridos apresentaram severidades similares quando inoculados com estes dois (Tabela 3). O híbrido Premium Flex, por exemplo, foi o mais resistente à $S$. macrospora considerando esses dois isolados, apresentando severidade de 4,2\% para Lages e 5,8\% para Vacaria. Para os demais isolados, este híbrido não se manteve entre os mais resistentes, apresentando severidade da mancha foliar de macrospora de 10,6\% para o isolado de Quilombo e 18,4\% para Campinas do Sul, encaixandose no grupo mais suscetível à doença. Fato semelhante ocorreu para os híbridos P30F53 e DKB350 YG posicionados no grupo dos mais resistentes para os isolados de Vacaria e de Lages. Para os isolados Quilombo e Campinas do Sul, estes híbridos enquadraram-se no grupo daqueles mais suscetíveis (Tabela 2). Esses resultados indicam que os isolados de $S$. macrospora provenientes de regiões diferentes de cultivo de milho apresentam variabilidade na agressividade.

. O equilíbrio entre a resistência do genótipo e a agressividade do isolado pode ser importante na discriminação de genótipos resistentes ou suscetíveis em programas de melhoramento genético (17). Os isolados geralmente são mais agressivos em seus locais de origem. Contudo, diferenças de agressividade podem ser observadas em alguns anos, devido às condições ambientais e a concentração de inóculo no ambiente (14). De modo contrário, outras cultivares se comportaram de maneira semelhante para todos os isolados, indicando que estas cultivares mantém a característica de resistência ao patógeno independente do isolado utilizado. Este fator é importante em programas de melhoramento, pois indicam que determinado material genético é estável e pode apresentar-se resistente em regiões geográficas distintas (22). 
Tabela 2: Severidade da mancha-de-macrospora em 25 híbridos de milho avaliada no estádio V4, inoculados com quatro isolados do fungo oriundos dos municípios de Lages, Vacaria, Quilombo e Campinas do Sul. Lages, SC, 2011

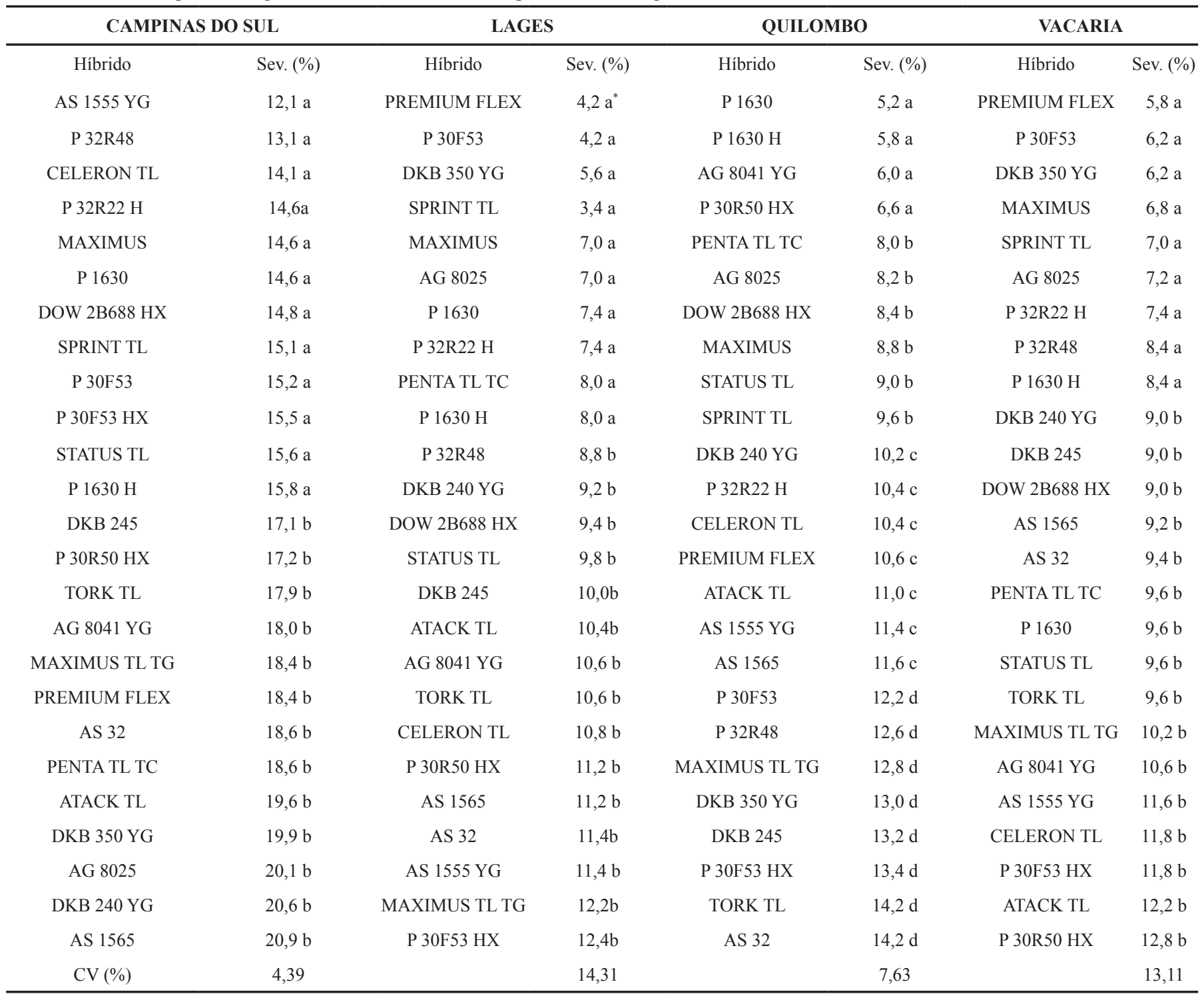

* Médias seguidas pela mesma letra na coluna não diferem entre si pelo teste $\operatorname{Scott} \operatorname{Knott}(\mathrm{p}<0,05)$.

Tabela 3. Mancha-de-macrospora comparando os quatro isolados de Stenocarpella macrospora considerando a severidade média de 25 híbridos de milho. Lages, SC, 2011

\begin{tabular}{cccc}
\hline Inóculo & Severidade (\%) & Isolados & Severidade (\%) \\
\hline Lages & $8,98^{\text {ns }}$ & Vacaria & $9,14^{*}$ \\
Vacaria & 9,14 & Quilombo & 10,27 \\
$\boldsymbol{C V}(\%)$ & 18,86 & $\mathrm{CV}(\%)$ & 14,62 \\
Lages & $8,98^{*}$ & Vacaria & $9,14^{*}$ \\
Quilombo & 10,27 & Campinas & 16,82 \\
CV (\%) & 15,19 & CV (\%) & 13,60 \\
Lages & $8,98^{*}$ & Campinas & $16,82^{*}$ \\
Campinas & 16,82 & Quilombo & 10,27 \\
\hline CV (\%) & 14,23 & CV (\%) & 8,85 \\
\hline
\end{tabular}

*Diferem estatisticamente entre si pelo Teste $\mathrm{F}$ a $5 \%$ de probabilidade.
Estudos da variabilidade genética de híbridos à reação da manchade-macrospora são importantes para identificar genótipos mais promissores que podem ser usados em futuros estudos em programas de melhoramento de milho, buscando minimizar os danos causados por S. macrospora. No entanto, a identificação de genótipos com menor suscetibilidade pode ser uma opção imediata para uso naquelas regiões com ocorrência generalizada da mancha-de-macrospora.

\section{AGRADECIMENTOS}

Agradecemos à Universidade do Estado de Santa Catarina UDESC por ter proporcionado a oportunidade de desenvolver este trabalho, no âmbito do seu programa de pós-graduação e por ter, durante esse período, oferecido toda base acadêmica e apoio,além de condições técnicas e logísticas para seu desenvolvimento do trabalho. Ao Conselho Nacional de Desenvolvimento Científico e Tecnológico - CNPq, pela concessão de bolsa de Produtividade em Pesquisa aos professores 
Dr. Ricardo Trezzi Casa e Ph.D. LuisSangoi e à Coordenação de Aperfeiçoamento de Pessoal de Nível Superior- CAPES, pela concessão de bolsa de mestrado aos alunos Daiana Bampi e Giovani Jian Piletti.

\section{REFERÊNCIAS BIBLIOGRÁFICAS}

1. Bampi, D.; Casa R. T.; Wordell Filho, J. A.; Kuhnem Junior, P. R.; Piletti, G. Relação entre a mancha de macrospora na folha da espiga e o rendimento e a sanidade de grãos de milho. In: Reunião Técnica Catarinense de Milho e Feijão, 8, 2011. Chapecó. Resumos... Chapecó: Epagri, 2011. p. 7-12.

2. Blum, L. E.; Sangoi, L.; Amarante, C. V. T.; Arioli, C. J.; Guimarães, L. S. Desfolha, população de plantas e precocidade do híbrido afetam a incidência e severidade de podridões de colmo. Ciência Rural, Santa Maria, v. 33, n. 5, p. 805-811, 2003.

3. Brunelli, K. R.; Athayde, C. S.; Cavalcanti, L. S.; Ferreira, P. T. O.; Camargo, L. E. A. Germinação e penetração de Stenocarpella macrospora em folhas de milho. Fitopatologia Brasileira, Fortaleza, v. 30, n. 2, p. 187-190, 2005.

4. Casa, R. T. ; Bampi, D. ; Kunhen Junior, P. R. ; Sangoi, L ; Blum, M. ; Wordell Filho, J. A. . Mancha-de-macrospora do milho no sul do Brasil. Revista Plantio Direto, Passo Fundo, v. 125, n.1, p. 13-17, 2011.

5. Casa, R.T.; Reis, E. M.; Kuhnem Junior, P.R.; Hoffmann, L.L. Doenças do milho: guia de campo para identificação e controle. Lages: Graphel, 2010. 79 p.

6. Casa, R.T.; Reis, E.M.; Zambolim, L. Decomposição dos restos culturais do milho e sobrevivência saprofítica de Stenocarpella macrospora e $S$. maydis. Fitopatologia Brasileira, Fortaleza, v. 28, n. 4, p. 355-361, 2003.

7. Casa, R.T.; Reis, E.M.; Zambolim, L. Dispersão vertical e horizontal de conídios de Stenocarpella macrospora e Stenocarpella maydis. Fitopatologia Brasileira, Lavras, v. 29, n. 2, p.141-147, 2004.

8. Casa, R.T; Reis, E.M; Zambolim, L. Doenças do milho causadas pelo gênero Stenocarpella. Fitopatologia Brasileira, Brasilia, DF, v. 31, n. 5, p. 427-439, 2006.

9. COMPANHIA NACIONAL DE ABASTECIMENTO - CONAB, Brasil. Indicadores da Agropecuária, Brasília, DF, 2010. Disponível em:<http://www.conab.com.br>. Acesso em: 21 ago. 2011.

10. Cruz, J.C.; Queiroz, L.R.; Pereira Filho, I.A. Milho: cultivares para 2010/2011. Sete Lagoas: Embrapa, CNMPMS, 2010. Disponível em: <http : / / www . cnpms . embrapa . br/milho/cultivares/.> Acesso: 06 fev 2011.

11. Eddins, A. H. Dry rot of corn caused by Diplodia macrospora Earle. Phytopathology, St. Paul, v. 20, n. 3, p. 439-448, 1930.

12. Fancelli, A. L.; Dourado Neto, D. Fisiologia da produção e aspectos básicos de manejo para alto rendimento. In: SANDNI, I. E.; FANCELLI, A. L. Milho: estratégias de manejo para a região sul. Guarapuava: Fundação Agrária de Pesquisa Agropecuária, 2000, p. $103-115$.

13. Fernandes, F. T.; Oliveira, E. Principais doenças na cultura do milho. Sete Lagoas: Embrapa, CNPMS, 1997. 80 p. (Circular Técnica, 26).

14. Kappelman, A. J.; Thompson, D. L.; Nelson, R. R. Virulence of 20 isolates of Diplodiazeae as revealed by stalk rot development in corn. Crop Science, Madison, v. 5, n. 1, p. 441-443, 1965.

15. Koehler, B. Natural mode of entrance of fungi into maize ears and some symptoms that indicate infection. Journal Agricultural Research, Washington, DC, v. 64, n. 8, p. 421-442, 1942.

16. Latterell, F. M.; Rossi, A. E. Stenocarpella macrospora (=Diplodia macrospora) and $S$. maydis ( $=D$. maydis) compared as pathogens of corn. Plant Disease, St. Paul, v. 67, n. 7, p. 725-729, 1983.

17. Maxwell, J.D.; Thompson, D.L. Mutual balance between tester resistance and isolate virulence the evaluation of corn inbreds for Diplodia stalk rot. Crop Science, Madison, v.14, n.4, p. 594-595, 1974.

18. Olatinwo, R.; Cardwell, K.; Menkir, A.; Deadman, M.; Julian, A. Inheritance of resistance to Stenocarpella macrospora(Earle) ear rot of maize in the mid-altitude Zone of Nigeria. European Journal of Plant Pathology, Dordrecht, v.105, n.6 , p.535-543, 1999 b.

19. Olatinwo, R.O.; Cardwell, K.F.; Deadman, M.L; Julian, A.M. Epidemiology of Stenocarpella macrospora (Earle) Sutton on maize in the Mid-altitude Zone of Nigeria. Journal of Phytopathology, Berlin, v.147, n.6, p.347-352, 1999a.

20. Pascual, C.B.; Guzman. P.S.; Salazar, A.M. Reliable and economical inoculum production method and disease resistance evaluation techniques to Stenocarpella macrospora in maize. Journal of Tropical Plant Pathology, Los Baños, v.38, n.1, p,1-8, 2002.

21. Paterniani, M. E. A. G. Z.; Sawazaki,E.; Dudienas, C. Duarte, A. P.; Gallo, P. B. Diallel crosses among maize lines with emphasis on resistance to foliar diseases. Genetics and Molecular Biology. Ribeirão Preto, v.23, n.1, p.381-385, 2000.

22. Pinto, R. J. B. Introdução ao melhoramento genético de plantas. 2. ed. Maringá: EDUEM, 2009. v. 1, 351 p.

23. Reis, E.M.; Casa, R.T.; Bresolin, A.C.R. Manual de diagnose e controle de doenças do milho. 2. ed. Lages: Graphel. 2004. 144 p.

24. Ritchie, S. W. et al. How a corn plant develops. Ames: Iowa State University of Science and Technology, 1993. 26 p. (Special Report, n. 48).

25. Shurtleff, M.C. Compendium of corn diseases. St. Paul. American Phytopathological Society, 1992. 105 p.

26. Sutoyo. Resistance of corn in cultivar/lines from Indonésia and the Philippines to Stenocarpella leaf blight (Stenocarpella macrospora). In: ZAIDI, P.H.; AZRAI, M.; PIXLEY, K. Maize for Azia: emerging trents and technologies, Makassar: Board, 2010. p. 669.

27. Tollenaar, M. Is low plant density a stress in maize? Maydica, Ames, v. 37, p. 305-311, 1992.

28. Wordell Filho, J. A. Resistência de cultivares de milho (Zea mays $L)$ a antracnose foliar no estádio de plântula. Agropecuária Catarinense, Florianópolis, v.23, n.1, p.53- 57, 2010. 